\title{
Beyond simple, easy, and fast Reflections on teaching Summon
}

I n April 2011, the Bowling Green State (BGSU) University Libraries (UL) selected Summon, Serials Solutions' Web-scale discovery service, to unlock local collections and provide Google-like access to our resources. Soon after acquiring the service and briefly piloting it, with very little beta testing, the service was fully functional-just in time for the academic year. Not only did librarians agree to a full implementation by that deadline, but they also determined that it would be the default search box on the homepage, raising the stakes for this project even higher.

The aggressive timeline and Summon's central placement on the homepage presented a significant challenge for reference and instruction librarians, who had little lead time to explore, understand, and incorporate this powerful new tool into their teaching materials and repertoires. At no time in the past had the UL decided to make such a large-scale change on such a compressed timeline. Coupled with local decisions to modify Summon configurations (on an almost daily basis at some points) and Serials Solutions' two-week enhancement cycle, the timeline forced librarians to be nimble, flexible, and learn on the fly. While Serials Solutions promotes Summon as "Simple. Easy. Fast." for end users, implementation was anything but easy and simple (though it was fast) for reference and instruction librarians who wanted to make the most of its potential for researchers at all levels. ${ }^{1}$

\section{A parallel project: A professional development learning community for instruction librarians}

While many librarians in the UL were involved in the Summon implementation proj- ect, a discussion about reflective practice and its importance in teaching and learning was taking place among the instruction librarians who were engaged in a learning community intended to promote professional development. Jenny Moon defines reflection as "a form of mental processing that we use to fulfill a purpose or to achieve some anticipated outcome. It is applied to gain a better understanding of relatively complicated or unstructured ideas and is largely based on the reprocessing of knowledge, understanding and possibly emotions that we already possess."

Char Booth, in her monograph on instructional literacy, as well as Beth S. Woodard and Lisa Janicke Hinchliffe, in their chapter on teaching improvement, emphasize the need for librarians to develop reflection as a critical habit of mind and a means to continuously improve teaching abilities. ${ }^{3}$

\section{A perfect storm: Reflecting about teaching Summon}

The introduction of the new instruction learning community and the adoption of Summon afforded UL librarians a unique opportunity to put theory to practice, reflecting upon Summon teaching strategies in the period shortly after implementation. Our purpose was to

\footnotetext{
Catherine Cardwell is director of libraries at Ohio Wesleyan University, e-mail: cardcat@owu.edu, she was the coordinator of instruction at Bowling Green State University through December 2011; Vera Lux is reference and instruction librarian, e-mail: vlux@bgsu. edu, and Robert J. Snyder is reference and instruction librarian, e-mail: robjsny@bgsu.edu, at Bowling Green State University
}

() 2012 Catherine Cardwell, Vera Lux, and Robert J. Snyder 
apply a slightly modified version of Booth's three-question reflection exercise after each Summon instruction interaction in order to determine what worked well, what didn't work well, and what we would do differently in future interactions. ${ }^{4}$ After each instruction encounter that included Summon, the librarians filled out a brief Google Form to note the type of interaction, the course name and number (if applicable), and the response to the three reflection questions. In this way, we were able to take a purposeful approach to the manner in which we taught this new resource by reflecting on the results and immediately revising and applying what we had learned to the next interaction.

We taught Summon to a variety of constituent groups (students, faculty, and staff) and in a variety of venues (one-shot class sessions, workshops, learning communities, and individual interactions). Although we considered extending this project to point-of-need instruction at the reference desk, we found that we rarely turned to Summon at the desk, relying instead on subject-specific databases, catalog searches, and other resources to satisfy the needs of patrons. Therefore, the results of our reflective practice activity do not include reference desk transactions.

Even though all three authors incorporated Summon into our teaching, we used various approaches, either starting with Summon and moving to discipline-specific resources or starting with a class LibGuide and moving to Summon. Some workshops with faculty focused solely on Summon. The purpose and scope of the session determined the approach used, rather than any type of predefined script.

\section{Undergraduate experiences post- instruction}

Several patterns emerged from our reflections, particularly when we grouped our experiences by the research expertise of our audience. In our sessions with firstand second-year undergraduates, we found that these students were highly receptive to working with Summon. They appreciated the ability to search in one place for a variety of resource types, and appeared naturally comfortable with searching multiple formats simultaneously. In retrospect, we determined that they might benefit from additional explanation about the differences between publication types, as discerning differences seemed complicated by the lack of context in the online environment. In the future we also intend to encourage students to think beyond source format by stressing the importance of evaluating information and choosing appropriate sources based on the purpose of an assignment.

During sessions that included time for individual or group hands-on searching, lower-division undergraduates gravitated to Summon, even though multiple library resources had been demonstrated. These experiences are not surprising considering that the 2009 Project Information Literacy report on student information-seeking behavior found that undergraduate students seek efficiency in their searching and, for ease of use, turn to library databases to meet instructor expectations and to find full-text resources online. ${ }^{5}$ At the UL, we marketed Summon for its Google-like interface, full text access, and ease of use, and this was likely to draw in these beginning students.

In two one-shot sessions comprised of mostly first-year students, we experimented with using Summon as a pre-search tool for topic exploration following Allison J. Head and Michael B. Eisenberg's recommendation that information literacy instruction should focus more on the beginning stages of the research process. ${ }^{6}$ While our experiences with this approach were limited, in both instances we found it difficult to teach topic exploration techniques with Summon as effectively as we had with other resources, such as EBSCO's visual search, without overwhelming novice researchers. In future sessions we plan to investigate the use of Summon as a topic-discovery tool with more advanced users, exploring the subject facets to find narrower and additional search terms. 
Upper-division undergraduates and beginning graduate students also found Summon effective and easy to use. These students were more likely than beginning undergraduates to have had experience using library resources and were receptive to the possibility of streamlining their research process. Teaching Summon after the various relevant catalogs and databases further highlighted the benefits of the inclusive Summon search. However, in some cases we found that students planned to continue to first use the "go-to" resources with which they had more longstanding familiarity, despite their appreciation for Summon.

We anticipated this outcome given the predominance of EBSCO databases in Ohio and in light of Head and Eisenberg's finding that students who experience success with a set of information tools continue to rely on those resources regardless of the research context. ${ }^{7}$ For example, in an introductory session with new graduate students, the class reported that they would continue to use, Google Scholar as their primary research tool despite finding Summon easy to use, efficient, and powerful.

Faculty and more experienced graduate students, particularly those in interdisciplinary programs, appreciated Summon's ability to cut across information silos and retrieve results from a wide variety of disciplines in one search box. Summon also proved to be a great tool for locating materials from inaccurate or incomplete citations. Our advanced students and faculty loved the ease and flexibility of this feature, which is particularly useful when conducting literature reviews. Faculty who rely heavily on monographs appreciated our decision to turn on both public domain and copyrighted works in HathiTrust, as it helped them discover new materials and offered the possibility of online access. These advanced users also appreciated more nuanced explanations of the functionality and scope of Summon, but our more extensive explanations were not always clear to our audience. In response, graphic complements to the discussion were developed and made available in our Summon LibGuide in order to better illustrate which resources are and are not included in Summon search results.

One-shot library sessions were often the first time faculty were exposed to Summon, and they were frequently more engaged than in previous sessions. Two comments from faculty, in particular, stand out. One wrote in a follow-up e-mail: "I do love Summon. ... It has made me discover a whole new series of information." Another faculty member said that scholars in her discipline have been encouraging one another to branch out beyond their tried and true databases into those used in other disciplines. The "Database Recommender" feature in Summon was allowing her to explore new databases that she otherwise would not have considered.

\section{Improving instruction}

In addition to gaining an understanding of how different audiences could incorporate Summon into their search for information, our reflective activity helped us fine tune our own practice during our rapid implementation. One of the problems we encountered when teaching Summon was that Summon is not the most efficient starting point in all circumstances. And although we were aware of some of Summon's limitations, we encountered additional complications as we worked with classes with very specific assignments for which a different resource would be more useful.

For instance, Summon doesn't work well if you need to identify only articles in U.S. news sources, since it does not have finegrained limits like other databases. Therefore, one change we would make to our instruction sessions where we are featuring Summon is to better articulate what Summon is, and what it is not, in order to make clearer the times when there are other resources students should turn to for a particular task.

Another benefit of the reflective activity was that we were able to contribute observations based on user responses and experiences to ongoing conversations in the UL 
about technical issues, some of which were based on local implementation decisions.

For example, all users anywhere can search the BGSU Summon installation but are not asked to authenticate until they click on a link for full text. The Summon implementation team found having the ability to search Summon installations at other institutions invaluable as the UL planned its own work. Unfortunately, this caused some linking problem for wireless users on campus and for all users off campus. The UL consequently added information to the library homepage about authenticating before searching. This small information change solved numerous problems, in the classroom and beyond.

On a different note, the implementation team also decided to turn on the "1-click" to full text option for all browsers except Internet Explorer. Usually the UL attempts to achieve a consistent user experience across browsers, but in this case, the team believed it was important for users to have the opportunity to take full advantage of "1-click" to full text. We incorporated information about this browser limitation in our print materials and instruction sessions, pointing users to preferred browsers whenever possible to take full advantage of Summon functionality. Given the potential complexity of the information on our link resolver page when "1-click" to full text does not work, our library created more self-guided help for users needing to decipher information. In both instances, the observations we recorded in our three-part reflection helped us refine teaching materials and explanations for users.

\section{Conclusion}

In our case, Summon is living up to Serials Solutions' claim that it is simple, easy, and fast for users. As instruction librarians, we could have based our instruction and interactions with students and faculty on that premise. However, as a consequence of our reflective practice activity, we developed a more nuanced, sophisticated understanding of its capabilities and limitations and, in the end, learned that Summon can be much more than a simple tool for novice users.

\section{Notes}

1. SerialsSolutions. Summon, accessed October 1, 2011, www.serialssolutions. com/assets/resources/summon-brochure -web.pdf.

2. Jenny Moon, "Guide for Busy Academics no.4. Learning Through Reflection" (Higher Education Academy, 2005), 1, www.heacademy.ac.uk/resources/detail /resource_database/id69_guide_for_busy _academics_no4_moon.

3. Char Booth, ReflectiveTeaching, Effective Learning: Instructional Literacy for Library Educators (Chicago: American Library Association, 2011); Beth S. Woodard and Lisa Janicke Hinchliffe, "Teaching the Teachers: Developing a Teaching Improvement Program for Academic Librarians," in The Expert Library: Staffing, Sustaining, and Advancing the Academic Library in the 21st Century, eds. Scott Walter, Karen Williams (Chicago: Association of College and Research Libraries, 2010), 314-336.

4. Booth, Reflective Teaching, 19.

5. Allison J. Head and Michael B. Eisenberg, "Lessons Learned: How College Students Seek Information in the Digital Age" (Seattle, WA: Project Information Literacy, The Information School, University of Washington, 2009), 28, http://projectinfolit.org /pdfs/PIL_Fall2009_finalv_YR1_12_2009v2. pdf

6. Allison J. Head and Michael B. Eisenberg, "Truth Be Told: How College Students Evaluate and Use Information in the Digital Age" (Seattle, WA: Project Information Literacy, The Information School, University of Washington, 2010), 39, projectinfolit.org /pdfs/PIL_Fall2010_Survey_FullReport1.pdf

7. Head and Eisenberg, "Lessons Learned," 15 .

8. The handouts we created can be found in the "Information Resources" tab in our Summon LibGuide at http://libguides.bgsu. edu/summon. $\boldsymbol{n}$ 